\title{
Transition from Multi-portal to Uni-portal Video Assisted Thoracoscopic Surgery: A Modern Era Requirement
}

\author{
Javed Mirdad Tarar', Kashif Nadeem ${ }^{2}$, Durre Sadaf Khan ${ }^{3}$, Muhammad Saleem Iqbal ${ }^{4}$
}

1 Consultant Thoracic Surgeon, Aseer Central Hospital, Abha, Kingdom of Saudi Arabia

1 Manuscript writing

2 Consultant General Surgeon, Prince Mansoor Military Hospital, Taif Kingdom of Saudi Arabia

2 Data collection, Proof reading

Post Graduate Trainee, Department of Hematology, Combined Military Hospital, Multan Pakistan

Data collection, Compiling the results

4 Assistant Professor, Department of Surgery, Faisalabad Medical University, Faisalabad Pakistan

Final layout

\author{
Submitted for Publication: 25-08-202 \\ Accepted for Publication 18-12-2020 \\ CORRESPONDING AUTHOR \\ Dr. Javed Mirdad Tarar \\ Consultant Thoracic Surgeon, Aseer Central \\ Hospital, Abha Saudi Arabia \\ Email:drjavedtarar@yahoo.com
}

\section{ABSTRACT}

Background: Every passing day brings new innovations to medical science and Thoracic Surgery is no exception to it. We have witnessed gradual evolution in VATS from multiple ports to single port over the last two decades. Objective: To evaluate whether this evolution is worth in terms of minimizing the postoperative complication. Study Design: Prospective randomized observational trial. Settings: Aseer Central Hospital, Abha-Saudi Arabia. Duration: Two years and 6 months from September 15, 2017 to March 15, 2020. Methodology: A total of 68 patients were studied who were operated by same surgical team under identical operative environment. Both diagnostic and therapeutic VATS procedures were included in our study. Histologically proven Bronchogenic Carcinoma resection in order to exclude stage to stage bias. Results: Different variables including Anesthesia and operative times, blood loss and post-operative surgical complications were found to be same in both operative procedures. However, patients with Uni-portal VATS experienced much less pain post operatively, their chest drains were removed earlier and consequently they had shorter hospital stay over all. Conclusion: Uni-portal VATS has similar efficacy and safety as Multi-portal VATS yet it results in faster recovery and shorter hospital stay.

Keywords: U-VATS: Uni-portal Video Assisted Thoracoscopic surgery, M-VATS: Multi-portal video Assisted Thoracoscopic surgery.

How to Cite: Tarar JM, Nadeem K, Khan DS, Iqbal MS. Transition from Multi-portal to Uni-portal Video Assisted Thoracoscopic Surgery: A Modern Era Requirement. APMC 2020;14(4):357-60. DOI: 10.29054/ APMC/2020.999

\section{INTRODUCTION}

History has witnessed gradual transition and evolution ever since the first Thoracoscopy was performed almost a century ago. Jacobeus is credited for it when he in 1913, used a cystoscope in chest to break tuberculous adhesions of a patient. Although major diagnostic and therapeutic interventions were routinely performed by thoracotomy or multi portal VATS since then,1,2 it was only until year 2000 when Uni-portal technique was incorporated in VATS. Since then, the spectrum of U-VATS is increasing with intense pace. In year 2004 Roco and his colleagues performed first lung wedge resection via U-VATS. ${ }^{3}$ Gonzalez and his colleagues are credited with first Uniportal VATS lobectomy in year 2011. ${ }^{4}$

At present hundreds of pulmonary procedures are done worldwide each day by utilizing this single incision technique including much complex procedures including bronchial and vascular sleeve resections, bronchoplasties and pneumonectomies. 5,6,7

No wonder, this technique is a watershed between open and minimal invasive surgery since it carries the efficacy and safety of thoracotomy yet it has minimal complication rate as of VATS. Having better hand eye coordination and utility of direct tactile sensation of lung parenchyma, this technique has short learning curve and easy to master with.

\section{METHODOLOGY}

Study Design: Prospective randomized observational trial.

Settings: Aseer Central Hospital, Abha-Saudi Arabia.

Duration: Two year and 6 months from September 15, 2017 to March 15, 2020.

Sample Technique: Randomized sampling.

Sample Size: A total of 68 patients were studied who were operated by same surgical team under identical operative environment.

Inclusion Criteria: Both diagnostic and therapeutic VATS procedures were included in our study.

Exclusion Criteria: Histologically proven Bronchogenic Carcinoma resection in order to exclude stage to stage bias.

Spectrum of Video Assisted Thoracoscopic surgery procedures performed in our study is shown in Table 1. 
Table 1: Types of procedures performed $(n=68)$

\begin{tabular}{|c|c|l|}
\hline $\begin{array}{c}\text { No. of } \\
\text { Patients }\end{array}$ & Percentage & \multicolumn{1}{|c|}{ Disease entity / Condition } \\
\hline $\mathbf{1 4}$ & $20.58 \%$ & $\begin{array}{l}\text { Wedge lung resection for } \\
\text { Spontaneous Pneumothorax }\end{array}$ \\
\hline $\mathbf{1 1}$ & $16.17 \%$ & Pleural Biopsy \\
\hline $\mathbf{1 0}$ & $14.70 \%$ & Lung biopsy for Pulmonary nodule \\
\hline $\mathbf{0 9}$ & $13.23 \%$ & Decortication for Early Empyema \\
\hline $\mathbf{0 7}$ & $10.29 \%$ & Mediastinal Lymph node biopsy \\
\hline $\mathbf{0 7}$ & $10.29 \%$ & Sympathectomy for Hyperhidrosis \\
\hline $\mathbf{0 6}$ & $8.82 \%$ & $\begin{array}{l}\text { Lung biopsy for Interstitial lung } \\
\text { disease }\end{array}$ \\
\hline $\mathbf{0 5}$ & $7.35 \%$ & $\begin{array}{l}\text { Diaphragmatic hernia and } \\
\text { eventration }\end{array}$ \\
\hline
\end{tabular}

Surgical Procedure: General Anesthesia with single lung ventilation was achieved by means of double lumen endotracheal tube. We did not use $\mathrm{CO}_{2}$ insufflation in our procedures. Patient was placed in standard lateral decubitus position with protective padding and proper draping.

Uni-portal Technique: A 2.5 to $3 \mathrm{~cm}$ incision was made in $5^{\text {th }}$ intercostal space anteriorly sparing both the Serratus and Serratus muscles. Intercostal muscles were divided with diathermy and ipsilateral pleural cavity was entered with collapsed lung. No attempt was made to retract the intercostal space by means of metallic retractor, Alexis wound protector was used instead for soft tissue retraction. $5 \mathrm{~mm}, 30^{\circ}$ camera was used to get panoramic view of pleural cavity along with other instruments including harmonic scalpel, endoscopic staplers and suction/irrigation cannula etc. Thorough pleural cavity irrigation with warm saline and adequate hemostasis was secured and the pleural cavity was sealed over a chest tube.

Multi-portal Technique: After identical preparation and anesthesia as mentioned earlier, standard 3 ports were utilized including a $10 \mathrm{~mm}$ port for camera in $8^{\text {th }}$ ICS mid axillary line, and two $5 \mathrm{~mm}$ ports for instrumentation. Surgical procedures were carried on similar operative principles. Chest tube was placed before closure of the port sites. In both techniques each port site was infiltrated with Bupivacaine $0.25 \%$. All the patients were extubated in Operating room and were shifted to surgical floor without ICU requirement.

Post-Operative Course: Pain score was assessed on VAS scale, ranging from 0 to 10 depending upon the severity and intensity of pain. Injectable Paracetamol 1gm every 6 hourly was given as base line analgesia to both subsets of patients. In case of uncontrolled severe pain (VAS $\geq 7$ ) narcotic analgesia (Injection Tramadol 50mg) was given. Record was kept for timing, dosage and frequency of these narcotic analgesics. Early ambulation, breathing exercises and incentive spirometer was advised for all patients post operatively and daily CXRs were performed until chest drains were removed.

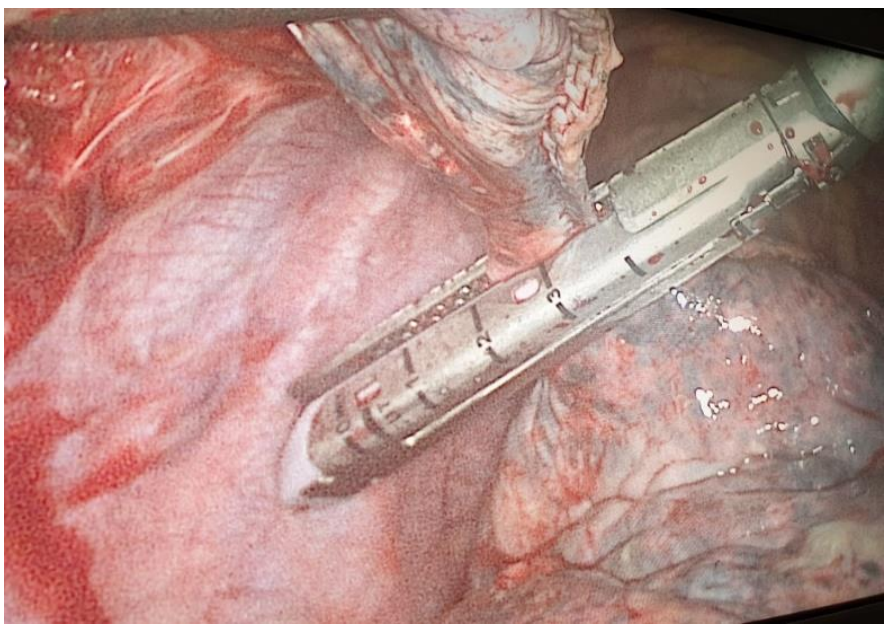

Figure 1: Uni-portal VATS: Lung Biopsy

Data Analysis: All the statistical data was analyzed on SPSS version 20.0. Using student $t$ test, chi square and Fisher's exact test, values were expressed as mean and median. Significance was defined if $\mathrm{P}$ value was $<0.05$.

\section{RESULTS}

Out of total 68 patients, 26 patients (38.23\%) had M-VATS and 42 patients $(61.76 \%)$ had U-VATS. 5 patients $(7.35 \%)$ with 3 in Uni-portal and 2 in multi-portal groups had to be converted to thoracotomy and were eventually excluded from the study. Our study results showed $46(67.64 \%)$ male and 22(32.35\%) female patients. Mean anesthesia time was 180 mins and 195 mins in U-VATS and M-VATS groups respectively. Operative time in both Uni-portal and multi-portal groups was almost same with no statistical difference. Postoperative complications occurred in 12 patients (17.64\%) with almost similar number of patients in both groups. Mean blood loss in patients who underwent U-VATS was $50 \mathrm{ml}$ in comparison to $80 \mathrm{ml}$ in M-VATS patients, however, this difference was statistically insignificant (Table 2).

Table 2: Post-operative variables and pain assessment

\begin{tabular}{|c|c|c|c|}
\hline Variable & U-VATS & M-VATS & P-value \\
\hline Anesthesia Time & $180 \pm 25$ mins & $195 \pm 20 \mathrm{mins}$ & 0.238 \\
\hline Operative Time & $90 \pm 20$ mins & $105 \pm 25$ mins & 0.421 \\
\hline Blood loss & $50 \pm 30 \mathrm{ml}$ & $80 \pm 20 \mathrm{ml}$ & 0.082 \\
\hline $\begin{array}{r}\text { Complications: } \\
\text { Atelectasis and } \\
\text { Pneumonia } \\
\text { Prolonged Air Leak } \\
\text { Pneumothorax } \\
\end{array}$ & $\begin{array}{l}5 \mathrm{pts} \\
2 \mathrm{pts} \\
3 \mathrm{pts} \\
0 \mathrm{pt}\end{array}$ & $\begin{array}{l}7 \mathrm{pts} \\
1 \mathrm{pt} \\
5 \mathrm{pts} \\
1 \mathrm{pt}\end{array}$ & $\begin{array}{l}1.12 \\
0.48 \\
0.39 \\
\end{array}$ \\
\hline Chest drain stay & $3 \pm 1$ days & $5 \pm 3$ days & 0.008 \\
\hline Hospital Stay & $4 \pm 2$ days & $7 \pm 4$ days & 0.013 \\
\hline $\begin{array}{l}\text { Pain: } \\
\text { VAS score } \\
\text { Narcotic use on Day } 1 \\
\text { Narcotic use on Day } 2\end{array}$ & $\begin{array}{c}3 \pm 2 \\
100 \pm 50 \mathrm{mg} \\
50 \pm 25 \mathrm{mg}\end{array}$ & $\begin{array}{c}6 \pm 3 \\
225 \pm 75 \mathrm{mg} \\
150 \pm 75 \mathrm{mg} \\
\end{array}$ & $\begin{array}{c}0.03 \\
0.006 \\
0.002 \\
\end{array}$ \\
\hline
\end{tabular}


We clearly noticed that pain score was less in patients with U-VATS and so was their post-operative narcotic analgesic requirement. Furthermore, we noted that patients in Multi-portal arm required prolonged chest tube drainage in contrast to Uni-portal i.e., 5 days vs 3 days respectively. This longer duration of chest tube stay in M-VATS group was translated into prolonged hospital stay as well.

\section{DISCUSSION}

To improve is to change; to be perfect is to change often.

"Sir Winston Churchill"

Medical science is witnessing innovations with every passing day and so does Thoracic Surgery. Modern anesthetic techniques, isolated pulmonary ventilation coupled with preoperative risk assessment with proper cardiac and pulmonary function testing, all these have made minimally invasive surgery in chest possible. Today we are equipped with VATS for virtually every Thoracic procedure including most complex ones like bronchial and vascular sleeve resections, bronchoplasties and even pneumonectomies.6,7 Rocco with his colleagues was the pioneer to perform first Uni-portal VATS pulmonary wedge resection in $2004 . .^{8}$ Afterwards, this evolution from multiple ports to single port in VATS kept ongoing and this technique gained popularity worldwide. In year 2006 surgical team at Duke University Medical Center published their experience of biportal VATS lung resection in 500 cases..$^{9}$ Gonzalez Rivas was the first one to perform single incision VATS lobectomy in 2010.4 Since then many centers are performing this procedure as routine with ongoing refinements and alterations. Now a days much smaller incision of 2.5 to 3 $\mathrm{cm}$ is utilized in U-VATS in contrast to originally described 4 to $5 \mathrm{~cm}$ incision. ${ }^{10} \mathrm{We}$ are practicing the same for our U-VATS procedures.

We noticed that the anesthesia/operative times and blood loss were almost similar in both the study groups and no statistically significant difference was found. These findings were exactly in accordance with previous studies. ${ }^{11,12}$ June Lee and colleagues, ${ }^{13}$ however, noticed that patients with Multi-portal VATS had more blood loss. The possible justification of this difference could be the judicious and cautious use of diathermy in port site creation in our study that resulted in minimal blood loss. We had a conversion rate of $7.35 \%$ from VATS to thoracotomy that is the same as observed in trials conducted before. ${ }^{14} 4$ out of 5 patients in whom conversion was contemplated were having empyema and the reason of conversion were dense adhesions and thick fibrotic peel which resulted in lung entrapment. We encountered overall complication rate of $17.64 \%$. These complications were not life threatening and were managed with expectant measures without the need of re-exploration. Incidence of these postoperative complications was similar in both groups and this finding was in accordance with previous studies. ${ }^{15}$

We clearly noticed that patients with U-VATS experienced much less pain in comparison to M-VATS and consequently they required much less top up narcotic analgesics. This difference was much significantly obvious in first 48 hours post operatively and similar observations were noted by others in past. ${ }^{16,17}$ No rib spreading with metallic retractors and avoidance of trocar pressure effects on N.V bundle are the mean reasons of this reduced pain in single incision VATS technique. Beside pain control benefit and reduced analgesic requirement, these patients had earlier ambulation out of bed that resulted in faster recovery. These patients showed better spirometry and breathing efforts that was translated in earlier chest drain removal and hence these patients were discharged from hospital earlier. Similar benefits in patients with U-VATS was shown in studies done in past. ${ }^{18,19}$ In our study the mean hospital stay in Uni-portal group was significantly shorter and these patients returned to their homes and jobs earlier. This indirectly was an evidence that Uniportal technique is more cost effective as was mentioned by Surendrakumar and his colleagues in 2017.20

The benefits of Uni-portal VATS in terms of efficacy and patient safety are undisputed, but does it take longer time to learn this technique? Interestingly the answer is a big NO. There is more natural hand eye coordination in same identical plane that makes this technique more versatile and easier to master in shorter duration of time. In contrast, Multi-portal VATS has trapezoidal instrumentation which makes this technique more difficult to learn and master with. ${ }^{21,22}$

\section{CONCLUSION}

Uni-portal VATS has the same efficacy and safety as Multi-portal VATS yet it has less post-operative pain, faster recovery and earlier hospital discharge.

\section{SUGGESTIONS / RECOMMENDATIONS}

It is highly recommended for Thoracic Surgeons to learn this technique and incorporate it in their surgical practices.

I hear and I forget. I see and I remember. I do and I understand. "Confucius, A Chinese Scholar"

\section{CONFLICT OF INTEREST / DISCLOSURE}

There is no conflict of interest to be declared.

\section{ACKNOWLEDGEMENTS}

The authors acknowledged the respected colleagues.

\section{REFERENCES}

1. McKenna RJ Jr, Houck W, Fuller CB. Video-assisted thoracic surgery lobectomy: experience with 1,100 cases. Ann Thorac Surg 2006;81(2):421-6. 
2. Swanson SJ, Herndon JE 2nd, D'Amico TA, et al. Video-assisted thoracic surgery lobectomy: report of CALGB 39802: a prospective, multi-institution feasibility study. J Clin Oncol. 2007;25(31):4993-7.

3. Rocco G, Martin-Ucar A, Passera E. Uni-portal VATS wedge pulmonary resections. Ann Thorac Surg. 2004;77(2):726-8.

4. Gonzalez D, de la Torre M, Paradela M, et al. Video-assisted thoracic surgery lobectomy: 3-year initial experience with 200 cases. Eur J Cardiothorac Surg. 2011;40(1):21-8.

5. Migliore M, Deodato G. A single-trocar technique for minimallyinvasive surgery of the chest. Surg Endosc. 2001;15(8):899-901.

6. Gonzalez-Rivas D, Fieira E, Delgado M, et al. Uni-portal videoassisted thoracoscopic sleeve lobectomy and other complex resections. J Thorac Dis. 2014;6(6):674-81.

7. Gonzalez-Rivas D, Yang Y, Sekhniaidze D, et al. Uni-portal videoassisted thoracoscopic bronchoplastic and carinal sleeve procedures. J Thorac Dis. 2016;8(82:210-22.

8. Rocco G, Martucci N, La Manna C, et al. Ten-year experience on 644 patients undergoing single-port (Uni-portal) video-assisted thoracoscopic surgery. Ann Thorac Surg. 2013;96(2):434-8.

9. Onaitis MW, Petersen RP, Balderson SS, et al. Thoracoscopic lobectomy is a safe and versatile procedure: experience with 500 consecutive patients. Ann Surg. 2006;244(3):420-5.

10. Yang HC, Noh D. Single incision thoracoscopic lobectomy through a $2.5 \mathrm{~cm}$ skin incision. J Thorac Dis. 2015;7(2):122-5.

11. Moon Y, AlGhamdi ZM, Jeon J, Hwang W, Kim Y, Sung SW. Nonintubated thoracoscopic surgery: initial experience at a single center. J Thorac Dis. 2018;10(6):3490-8.

12. Ahn S, Moon Y, AlGhamdi ZM, Sung SW. Nonintubated Uniportal video-assisted thoracoscopic surgery: a single-center experience. Korean J Thorac Cardiovasc Surg. 2018;51(5):344-9.

13. Lee J, Lee JY, Choi JS, et al. Comparison of Uni-portal versus Multiportal Video assisted thoracoscopic surgery Pulmonary segmentectomy. Korean J Thorac Cardiovas Surg. 2019;52(3):141-7.
14. Shaw JP, Dembitzer FR, Wisnivesky JP, Litle VR, Weiser TS, Yun J, et al. Video-assisted thoracoscopic lobectomy: state of the art and future directions. Ann Thorac Surg. 2008;85(2):705-9.

15. Ersen E, Kilic B, Kara HV, et al. Uni-portal versus multiport Videoassisted thoracoscopic surgery for anatomical lung resection: a glance at a dilemma. Videosurgery Miniinv. 2018;13(2):215-20.

16. Jutley RS, Khalil MW, Rocco G. Uniportal vs standard three-port VATS technique for spontaneous pneumothorax: comparison of post-operative pain and residual paraesthesia. Eur J Cardiothorac Surg. 2005;28(1):43-6.

17. M. Salati, A. Brunelli, F. Xium'e et al. Institutional report: thoracic general: Uni-portal video-assisted thoracic surgery for primary spontaneous pneumothorax: clinical and economic analysis in comparison to the traditional approach. Inter Cardio Thoracic Surgery. 20081;7(1):63-6.

18. Hirai K, Takeuchi S, Usuda J. Single-incision thoracoscopic surgery and conventional video-assisted thoracoscopic surgery: a retrospective comparative study of perioperative clinical outcomest. Eur J Cardiothorac Surg. 2016;49(1):37-41.

19. Louis SG, Gibson WJ, King CL, Veeramachaneni NK. Uniportal video-assisted thoracoscopic surgery (VATS) technique is associated with decreased narcotic usage over traditional VATS lobectomy. J Vis Surg. 2017;3:117.

20. Surendrakumar V, Martin-Ucar AE, Edwards JG, Rao J, Socci L. Evaluation of surgical approaches to anatomical segmentectomies: the transition to minimal invasive surgery improves hospital outcomes. J Thorac Dis. 2017;9(10):3896-902.

21. Bertolaccini L, Rocco G, Viti A, et al. Geometrical characteristics of Uni-portal VATS. J Thorac Dis. 2013;5(3):214-6.

22. Bertolaccini L, Viti A, Terzi A, et al. Geometric and ergonomic characteristics of the Uni-portal video-assisted thoracoscopic surgery (VATS) approach. Ann Cardiothorac Surg. 2016;5(2):11822. 